\title{
Improving the Performance of a Microstrip Antenna by Adding a Slot into Different Patch Designs
}

\author{
Mohammed J. Hakeem \\ Department of Electrical and Electronic Engineering \\ College of Engineering \\ University of Jeddah \\ Jeddah, Saudi Arabia \\ mjhakeem@uj.edu.sa
}

\author{
Mousaab M. Nahas \\ Department of Electrical and Electronic Engineering \\ College of Engineering \\ University of Jeddah \\ Jeddah, Saudi Arabia \\ mnahas1@uj.edu.sa
}

\begin{abstract}
Microstrip patch antennas are attractive for communication applications due to their small size, low cost, and easy fabrication. Regardless of the diverse usage of these antennas, their bandwidth and efficiency are still limited and need to be improved. Therefore, this paper aims to enhance the bandwidth and efficiency of a microstrip antenna by inserting a slot into various patch designs. Flame Retardant (FR4) material is used in the dielectric substrate and the antenna is fed by a microstrip line. Virtually, the antenna performance is attempted to be optimized through empirical investigations of feedline lengths, slot sizes and positions, and ground plane dimensions and locations. To achieve the results, the High Frequency Structure Simulator (HFSS) is used, and the paper concludes by showing that the antenna performance is enhanced by the slot, and the return loss is significantly reduced when the ground plane is moved to the front surface of the antenna.
\end{abstract}

\section{Keywords-antenna; microstrip; patch; slot}

\section{INTRODUCTION}

The use of microstrip patch antennas in wireless communications is increasing. Typically, a microstrip patch antenna comprises of a radiating patch on the front surface and a ground plane on the back side. A dielectric substrate is used between the patch and ground plane. There are different shapes that can be used for the patch, e.g. annular, square, rectangular, circular, semicircular, elliptical, diamond, hexagonal, triangular, and bowtie [1]. The microstrip antennas possess attractive features including the ease of fabrication and integration with RF devices, low profile, low weight, and low cost [2, 3]. Therefore, they are suitable for various communication applications such as cellular phones, Radio Frequency Identification (RFID) tags, satellite, Global Positioning System (GPS), missiles, and radar [4, 5].

Although the microstrip antennas are widely used, they still suffer from narrow bandwidth and low efficiency [1]. For instance, the bandwidth of the traditional microstrip antenna is calculated around $2-5 \%$ and the maximum gain is $\sim 7 \mathrm{~dB}$ by single patch [5]. This can be understood as the electromagnetic fringing occurs from two patch edges only. In practice, different antenna parameters can be responsible for improving the fringing, hence radiation. For example, decreasing the dielectric constant or increasing the substrate thickness results in the increase of the antenna bandwidth [6]. However, the substrate thickness cannot exceed $0.05 \lambda$ because the antenna will deliver the power into surface waves instead of transverse waves, and thus it will stop radiating. Another problem will arise due to the mutual coupling that reduces the efficiency of the antenna as well [7].

In general, the performance of a microstrip antenna largely depends on the patch geometry. Due to this, different patch shapes have been proposed including diamond, triangular, hexagonal, bowtie, circular, U-shaped, etc. [8-15]. Moreover, it has also been shown that inserting slots into the metallic parts of the antenna can enhance the radiation pattern significantly while simultaneously simplifying the overall design. For instance, a microstrip antenna was designed for UltraWideband (UWB) applications using different shapes of slot in the ground plane [16]. Another study proposed a wideband antenna through the insertion of a slot in the ground plane and stacked patch for the $2.5-3.19 \mathrm{GHz}$ application band [17]. Another design used a slotted ground with star and elliptical patches to create new frequency bands including the Long Term Evolution (LTE), Wireless Local Area Network (WLAN), and WiMAX [18]. More wideband and multiband designs have been recently presented that use a slotted ground plane as well [19-21]. Nevertheless, the insertion of (or cutting) a slot in the patch section itself has proven to be more useful and practical in enhancing the antenna performance. Such approach has been demonstrated in several researches for various frequency bands including WiMAX, WLAN, 3G, microwave, radar, and other application bands $[1,2,4,6,22-$ 31]. All these researches used slots in rectangular or circular patch shape with a ground plane being located in the back surface of the antenna. Therefore, there is a great potential in investigating different slotted-patch shapes, ground plane locations, slot sizes and positions, and feedline lengths. This paper aims to conduct such an investigation to improve the antenna resonance characteristics in the $1-12 \mathrm{GHz}$ frequency range that belongs to the Super High Frequency (SHF) band. According to the IEEE radio band designations, this frequency region mainly covers the $\mathrm{C}$-band and $\mathrm{X}$-band applications, 
which involve satellites, Wi-Fi, cordless telephones, surveillance, radar, and weather radar systems.

The microstrip patch antenna is likely to be fed by either a contacting or a non-contacting method. A contacting method utilizes a connecting element such as a coaxial cable or a microstrip line to feed the patch with RF power. In contrast, the non-contacting method involves the coupling of an electromagnetic field between the patch and a microstrip line [32]. This paper involves contact feeding because it is comparatively cheaper and easier to model and fabricate. The connecting element is a microstrip line since it yields better bandwidth in comparison to the coaxial cable and it can also be etched on the same substrate to provide a planar structure [33].

\section{Methodology}

The results of this research were obtained with the use of the HFSS software, which is a well-recognized design simulation platform for antennas. To start up, the initial dimensions of the different antenna sections were based on calculations and measurements obtained in a past study [34]. Then, the feedline and ground lengths varied between 3.7 and $25.7 \mathrm{~mm}$, whereas the feedline width was fixed at $2.8 \mathrm{~mm}$. The substrate dimensions are fixed at $1.6 \mathrm{~mm}$ height (thickness), $50 \mathrm{~mm}$ length, and $42 \mathrm{~mm}$ width to maintain a small overall size. The current study also makes use of an already presented approach for planar monopole antennas [35] in which the ground plane was moved to the front side of the antenna and the designer compared six different patch shapes (rectangular, circular, elliptical, diamond, hexagonal, and triangular) without adding a slot. In this project, we aim to improve the performance by cutting a slot into the same six patch geometries and dimensions using both ground-back and ground-front situations. The main issue is that the size and position of the slot has to be optimized, and there is no specific algorithm to define such parameters. To solve this issue in the HFSS, an optimization property is used where a huge number of slot values are compared over a short period of time. This feature is used in every experiment demonstrated below such that the slot dimensions and position along with the other antenna values (e.g. feedline and ground lengths) are all empirically optimized. The FR4 material is used in the dielectric substrate due to its availability and low cost. The dielectric constant is chosen to be 4.35 during the simulations.

\section{DESIGN AND RESUlTS}

The different patch designs were simulated in the following order: triangular, diamond, circular, elliptical, hexagonal, and rectangular. Each design is examined without and with a slot in the ground-back and ground-front condition respectively.

\section{A. Ground-Back Triangular Patch}

In the ground-back triangular patch without slot, the best empirical base width of the patch is $6 \mathrm{~mm}$ and the feedline length is $\sim 6 \mathrm{~mm}$, whereas the ground length is $13.7 \mathrm{~mm}$. The ground width is equal to the substrate width in all ground-back experiments. As a result, the minimum reflection coefficient (return loss) is $-16 \mathrm{~dB}$ and the frequency bandwidth is $0.7266 \mathrm{GHz}$. After adding a rectangular slot, the return loss is improved as the minimum reflection is reduced to $-36 \mathrm{~dB}$, and the bandwidth becomes $0.637 \mathrm{GHz}$. The best empirical length and width of the slot are 6 and $4 \mathrm{~mm}$ respectively, and the slot center is positioned at $(10,2,1.503) \mathrm{mm}$, given that $x$ is the vertical axis, $y$ is the horizontal axis, and $z$ is the patch thickness that is fixed throughout the paper. Figures 1 and 2 show the design and $\mathrm{S} 11$ results as taken directly from the HFSS for the ground-back triangular patch without and with slot respectively. Note that positive $x$ is towards the bottom in our view, while negative $x$ would be towards the top.

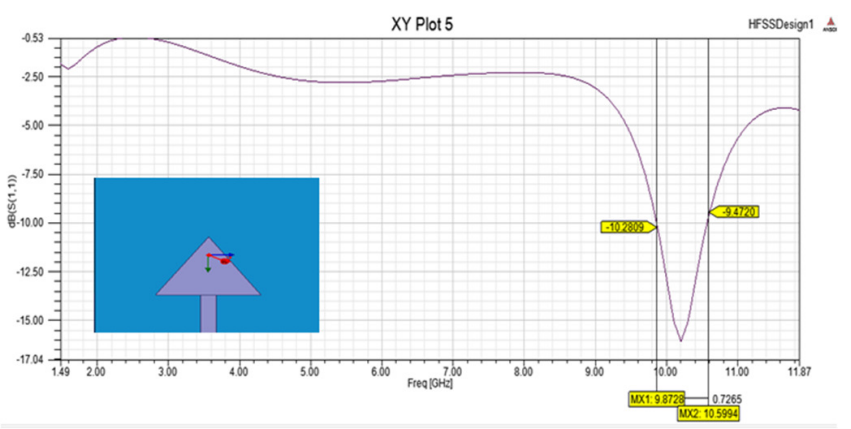

Fig. 1. Ground-back triangular patch without slot. Design and results.

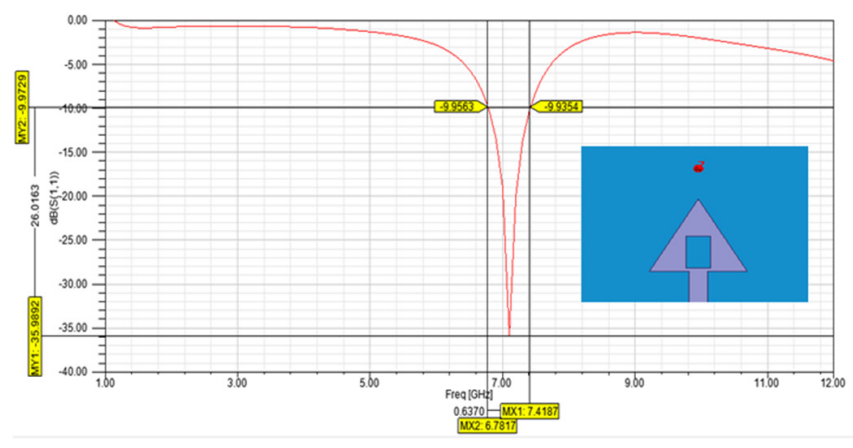

Fig. 2. Ground-back triangular patch with slot. Design and results.

\section{B. Ground-Front Triangular Patch}

The ground-front triangular antenna has an empirical feedline length of $13.77 \mathrm{~mm}$, whereas the ground length and width are 10.58 and $18 \mathrm{~mm}$ respectively. Note that these ground dimensions belong to one section since the entire front ground is composed of two symmetrical sections around the feedline. Without slot, the minimum reflection coefficient is $-26 \mathrm{~dB}$ and the bandwidth is $0.8847 \mathrm{GHz}$. These values improved after adding a rectangular slot. The minimum reflection was reduced to $-45.46 \mathrm{~dB}$ and the bandwidth was increased to $1.2428 \mathrm{GHz}$. The empirical length and width of the slot are 2 and $8 \mathrm{~mm}$ respectively, and the slot position is $(8,4,1.503) \mathrm{mm}$. Figures 3 and 4 show the design and results of the ground-front triangular patch without and with slot respectively.

\section{Ground-Back Diamond Patch}

The ground-back diamond antenna has an empirical feedline length of $13.7912 \mathrm{~mm}$ and a ground length of $13.7 \mathrm{~mm}$. Its minimum reflection without slot is $-13 \mathrm{~dB}$ and its bandwidth is $3.404 \mathrm{GHz}$. After adding a rectangular slot of $2 \mathrm{~mm}$ length and $8 \mathrm{~mm}$ width, the minimum reflection coefficient becomes $-16.69 \mathrm{~dB}$ and the bandwidth is increased to $4.9577 \mathrm{GHz}$. The 
optimal slot position is $(1,4,1.503) \mathrm{mm}$. Figures 5 and 6 show the design and results of the ground-back diamond patch without and with slot respectively.

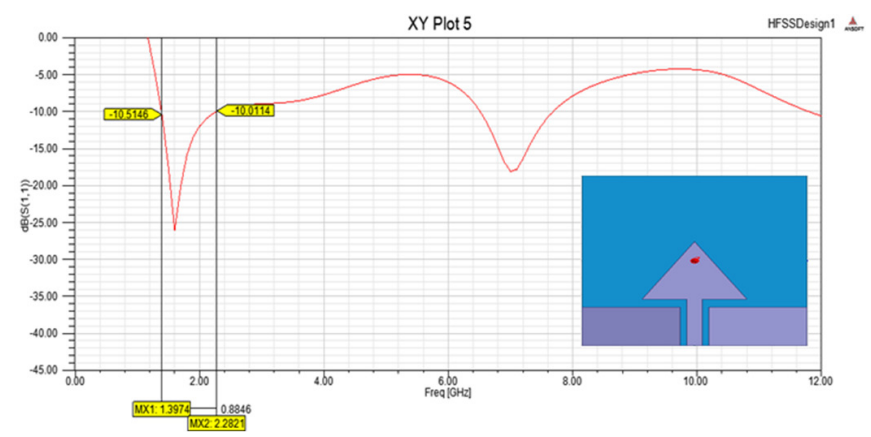

Fig. 3. Ground-front triangular patch without slot. Design and results.

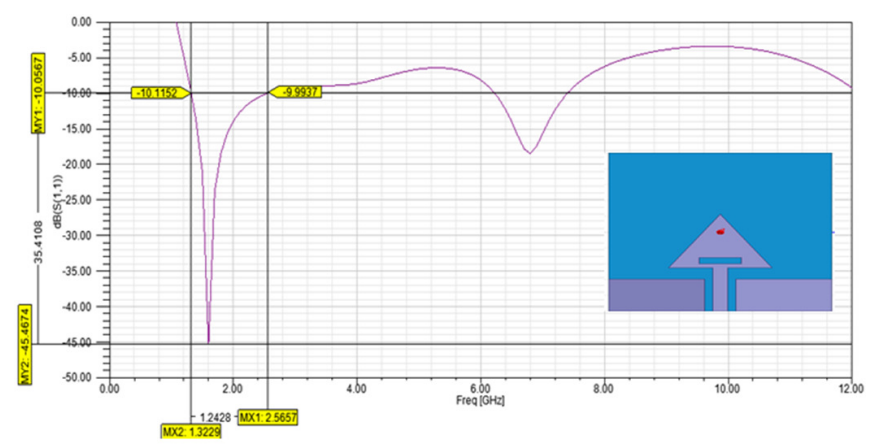

Fig. 4. Ground-front triangular patch with slot. Design and results.

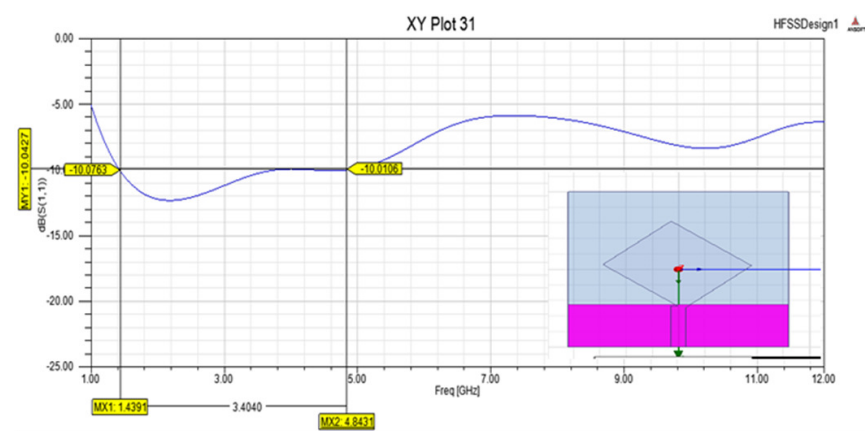

Fig. 5. Ground-back diamond patch without slot. Design and results.

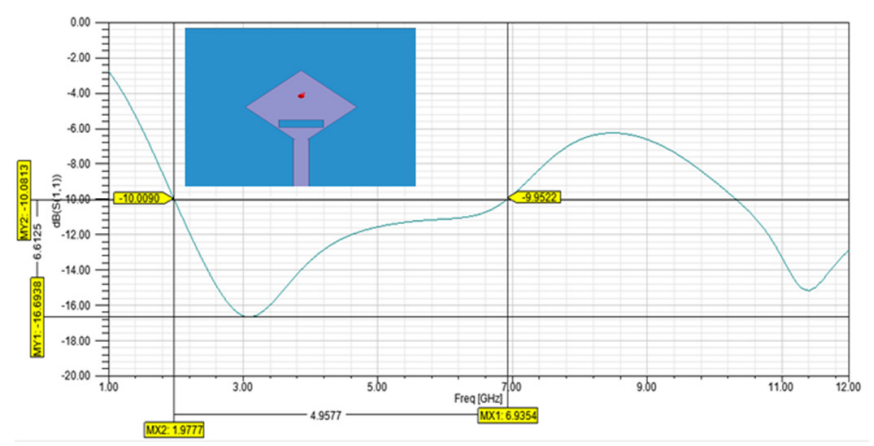

Fig. 6. Ground-back diamond patch with slot. Design and results.

\section{Ground-Front Diamond Patch}

The ground-front diamond patch has an optimal feedline length of $13.78 \mathrm{~mm}$, whereas the ground length and width are $13 \mathrm{~mm}$ and $19 \mathrm{~mm}$ respectively. The minimum reflection coefficient obtained by this setting is $-16 \mathrm{~dB}$, while the bandwidth is $2.2949 \mathrm{~dB}$. After adding a rectangular slot, the minimum reflection is decreased to $-22 \mathrm{~dB}$ and the bandwidth becomes $2.996 \mathrm{GHz}$. The empirical slot position is $(6,-4.1$, $1.503) \mathrm{mm}$, while its length and width are 2 and $8 \mathrm{~mm}$ respectively. The design and results of the ground-front diamond antenna without and with slot are shown in Figures 7 and 8 respectively.

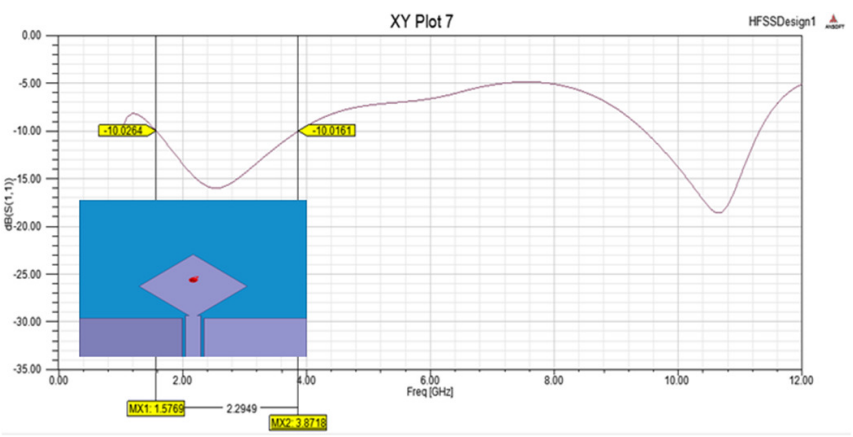

Fig. 7. Ground-front diamond patch without slot. Design and results.

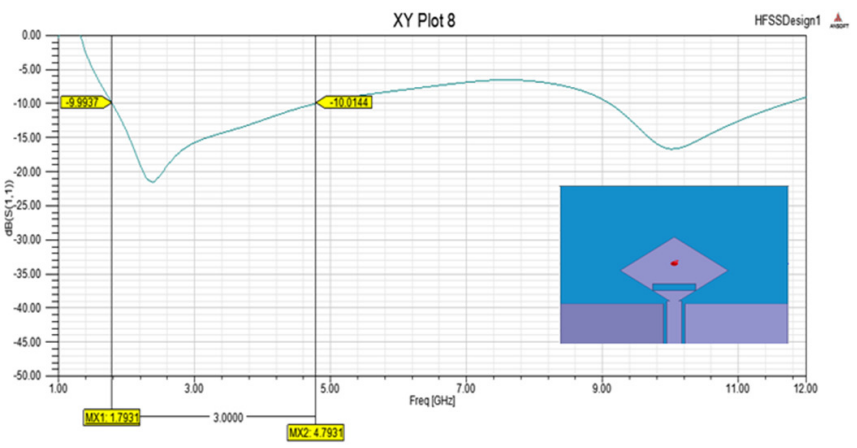

Fig. 8. Ground-front diamond patch with slot. Design and results.

\section{E. Ground-Back Circular Patch}

The ground-back circular patch has a feedline length and a ground length of $14.94 \mathrm{~mm}$ and $13.77 \mathrm{~mm}$ respectively. The minimum reflection coefficient achieved is $-18 \mathrm{~dB}$, while the bandwidth is $7.2718 \mathrm{GHz}$. After adding a rectangular slot with $2.5 \mathrm{~mm}$ length and $12 \mathrm{~mm}$ width, the minimum reflection is reduced to $-25.108 \mathrm{~dB}$ and the bandwidth is increased to more than $10.4978 \mathrm{GHz}$. The optimal slot position is $(4.6,6,1.503)$ $\mathrm{mm}$. Figures 9 and 10 show the design and results of the ground-back circular patch without and with slot respectively.

\section{F. Ground-Front Circular Patch}

In the ground-front circular patch without slot, the best feedline length is $13.7873 \mathrm{~mm}$, whereas the ground length and width are 13 and $19 \mathrm{~mm}$ respectively. The minimum reflection reaches $-37.8 \mathrm{~dB}$, while the bandwidth is $10.4006 \mathrm{GHz}$. After adding a circular slot, the minimum reflection is reduced to $-43.53 \mathrm{~dB}$ and the bandwidth becomes $2.4386 \mathrm{GHz}$. The slot is 
positioned at $(1,0,1.503) \mathrm{mm}$ and its best radius is $9 \mathrm{~mm}$. Figures 11 and 12 show the design and results of the groundfront circular antenna without and with slot.

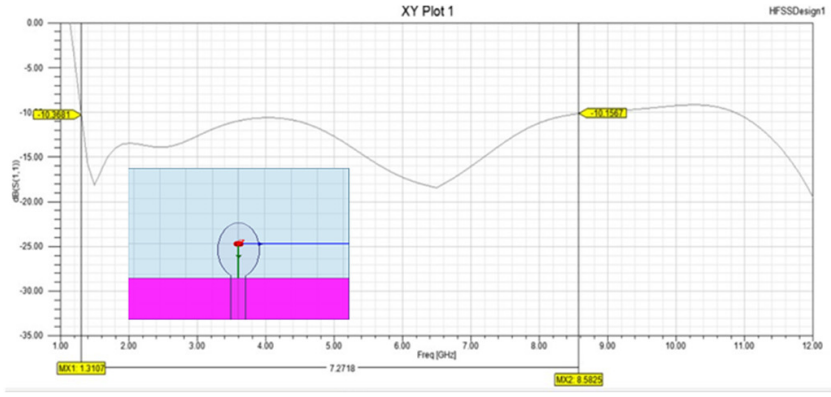

Fig. 9. Ground-back circular patch without slot. Design and results.

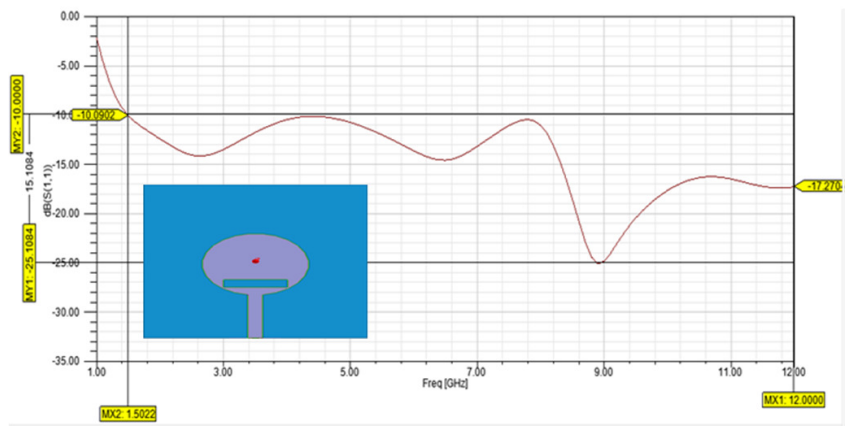

Fig. 10. Ground-back circular patch with slot. Design and results.

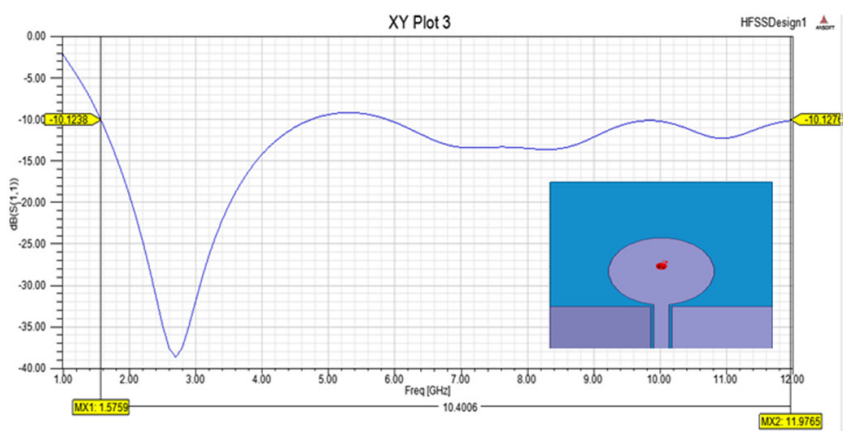

Fig. 11. Ground-front circular patch without slot. Design and results.

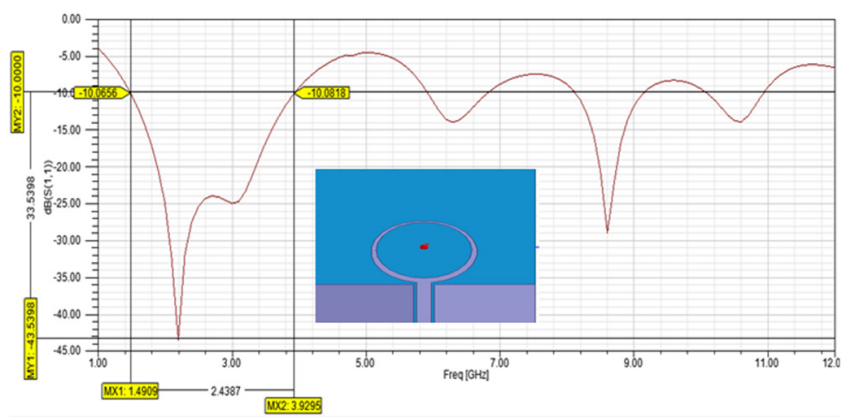

Fig. 12. Ground-front circular patch with slot. Design and results.

\section{G. Ground-Back Elliptical Patch}

In the ground-back elliptical antenna without slot, the best feedline length is $14.857 \mathrm{~mm}$, whereas the ground length is
$13.694 \mathrm{~mm}$. The major (vertical) patch radius is marked at $8.99 \mathrm{~mm}$. The minimum reflection obtained by this setting is $-16 \mathrm{~dB}$ and the bandwidth is $2.69498 \mathrm{GHz}$. After adding a circular slot with $1 \mathrm{~mm}$ radius at $(3,0,1.503) \mathrm{mm}$, the minimum reflection is reduced to $-20.1 \mathrm{~dB}$ and the bandwidth becomes $2.4321 \mathrm{GHz}$. Figures 13 and 14 show the design and results of the ground-back elliptical patch without and with slot respectively.

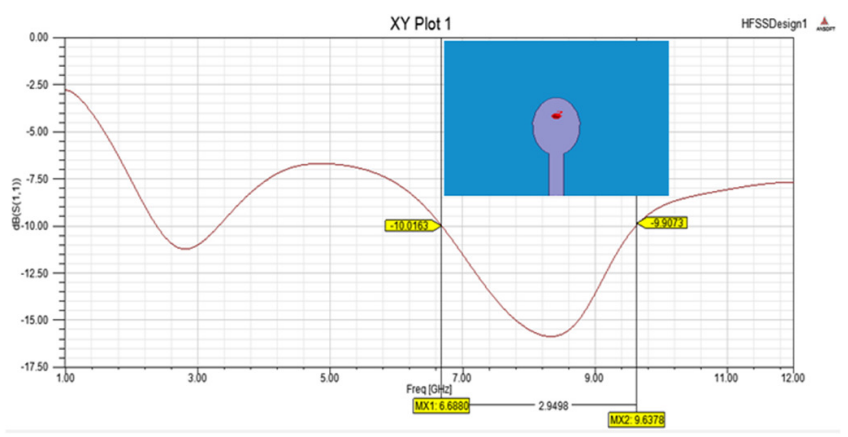

Fig. 13. Ground-back elliptical patch without slot. Design and results.

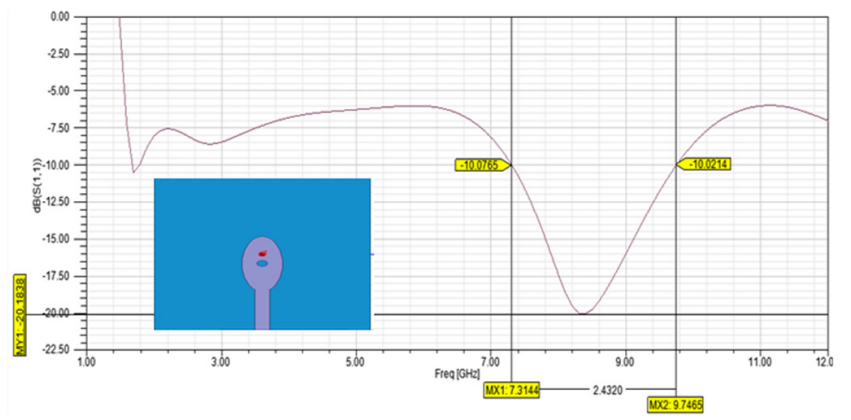

Fig. 14. Ground-back elliptical patch with slot. Design and results.

\section{H. Ground-Front Elliptical Patch}

The ground-front elliptical patch has a feedline length of $13.691 \mathrm{~mm}$, and ground length and width of 11.281 and $18.294 \mathrm{~mm}$ respectively. Without slot, the minimum reflection coefficient is $-28.3 \mathrm{~dB}$ and the bandwidth is $4.0545 \mathrm{GHz}$. After adding a rectangular slot with $15 \mathrm{~mm}$ length, $2 \mathrm{~mm}$ width at $(-4,-1,1.503) \mathrm{mm}$, the minimum reflection becomes $-26.33 \mathrm{~dB}$ and the bandwidth $3.3892 \mathrm{GHz}$. The design and results of the ground-front elliptical antenna without and with slot are shown in Figures 15 and 16.

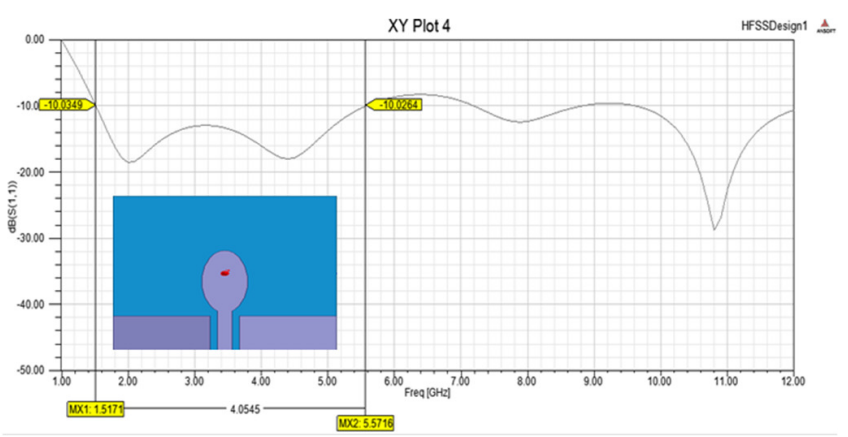

Fig. 15. Ground-front elliptical patch without slot. Design and results. 


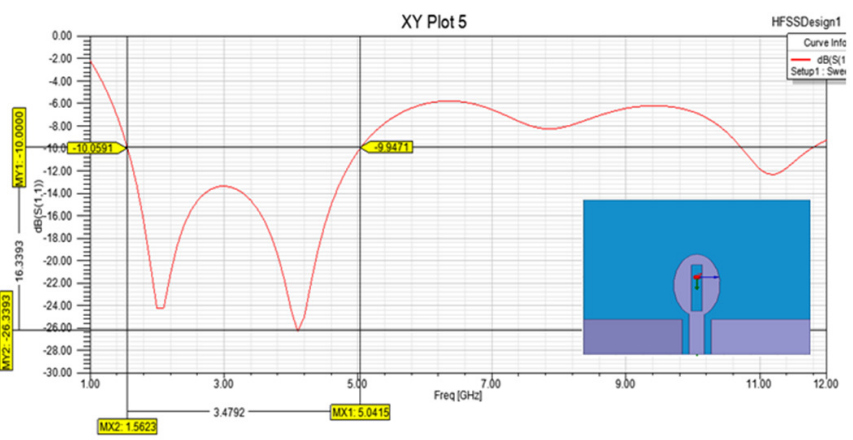

Fig. 16. Ground-front elliptical patch with slot. Design and results.

\section{Ground-Back Hexagonal Patch}

The ground-back hexagonal antenna has a feedline length of $13.79 \mathrm{~mm}$ and a ground length of $13.811 \mathrm{~mm}$. Initially, the minimum reflection coefficient is $-14 \mathrm{~dB}$ and the bandwidth is $4.9615 \mathrm{GHz}$. After adding a rectangular slot, the minimum reflection is significantly reduced to $-31.82 \mathrm{~dB}$ and the bandwidth increases to $5.9599 \mathrm{GHz}$. The best length and width of the slot are 3 and $10 \mathrm{~mm}$ respectively, while the slot is positioned at $(8,-5,1.503) \mathrm{mm}$. The design and results of the ground-back hexagonal patch without and with slot are shown in Figures 17 and 18 respectively.

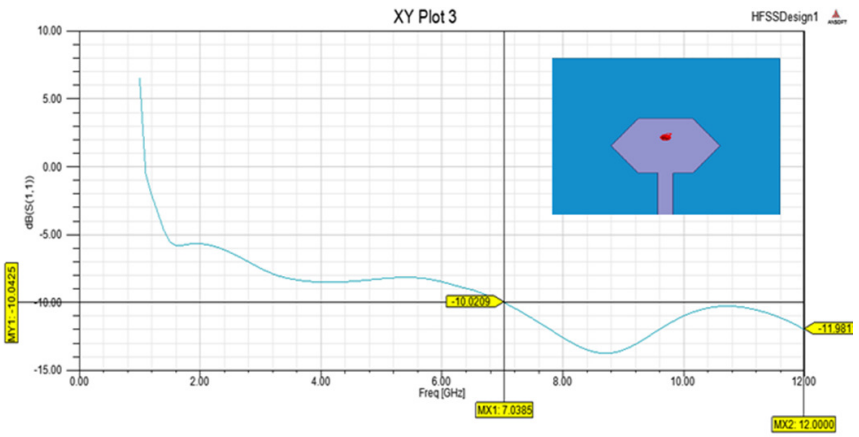

Fig. 17. Ground-back hexagonal patch without slot. Design and results.

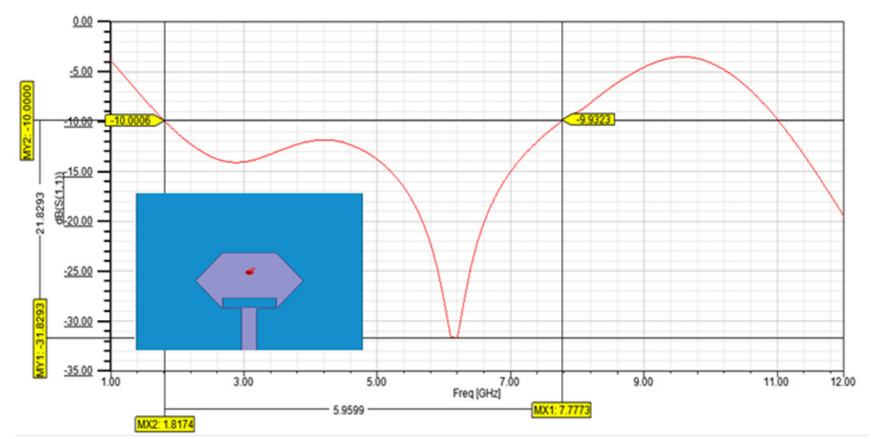

Fig. 18. Ground-back hexagonal patch with slot. Design and results.

\section{J. Ground-Front Hexagonal Patch}

The ground-front hexagonal patch has a feedline length of $13.7 \mathrm{~mm}$, a ground length of $11.42 \mathrm{~mm}$, and a ground width of $18.64 \mathrm{~mm}$. The minimum reflection in the results is $-48 \mathrm{~dB}$ and the bandwidth is $6.6282 \mathrm{GHz}$. After adding a rectangular slot, the minimum reflection coefficient is decreased to $-63.82 \mathrm{~dB}$ and the bandwidth is slightly increased to $6.7028 \mathrm{GHz}$. The slot is optimally positioned at $(3,0.5,1.503) \mathrm{mm}$, while its length and width are $3 \mathrm{~mm}$ and $1 \mathrm{~mm}$ respectively. The design and results of the ground-front hexagonal antenna without and with slot are shown in Figures 19 and 20 respectively.

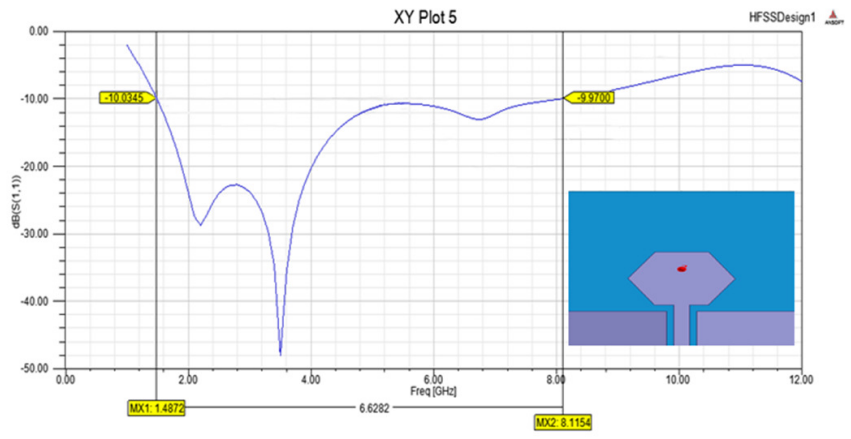

Fig. 19. Ground-front hexagonal patch without slot. Design and results.

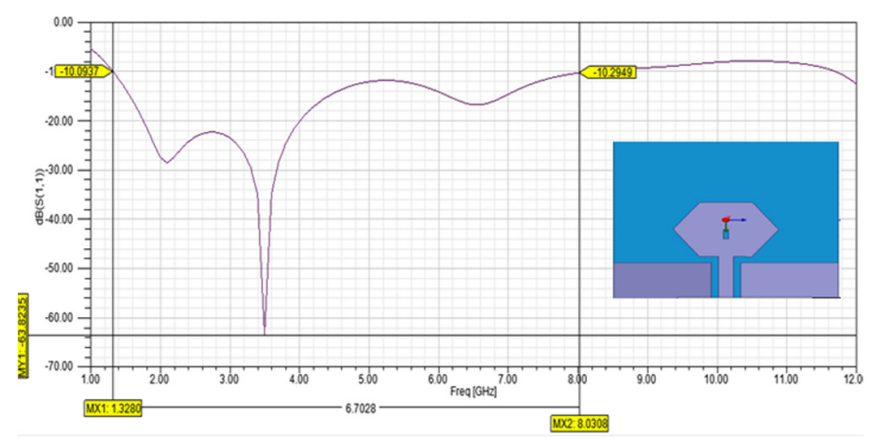

Fig. 20. Ground-front hexagonal patch with slot. Design and results.

\section{K. Ground-Back Rectangular Patch}

The ground-back rectangular antenna has a patch width of $8 \mathrm{~mm}$, a patch length of $7.9 \mathrm{~mm}$, a ground length of $12.85 \mathrm{~mm}$, and a feedline length of $13.67 \mathrm{~mm}$. The minimum reflection coefficient is $-16 \mathrm{~dB}$ and the bandwidth is $4.8413 \mathrm{GHz}$. After adding a rectangular slot, the minimum reflection reaches $-19.26 \mathrm{~dB}$, while the bandwidth becomes $4.6181 \mathrm{GHz}$. The slot is positioned at $(3,3,1.503) \mathrm{mm}$ and its length and width are 1 and $6 \mathrm{~mm}$ respectively. The design and results of the groundback rectangular patch without and with slot are shown in Figures 21 and 22 respectively.

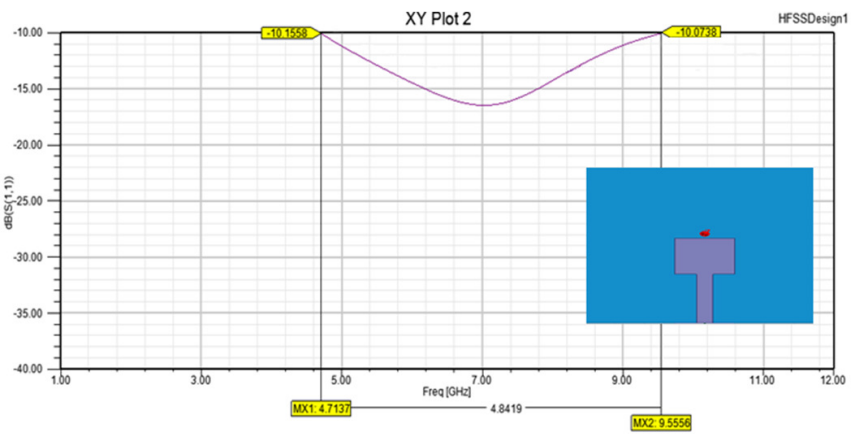

Fig. 21. Ground-back rectangular patch without slot. Design and results. 


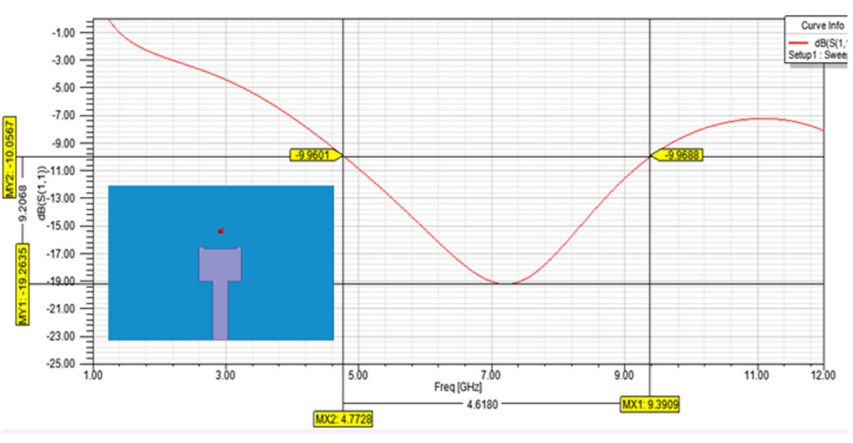

Fig. 22. Ground-back rectangular patch with slot. Design and results.

\section{Ground-Front Rectangular Patch}

In the ground-front rectangular antenna without slot, the feedline length is around $13.7 \mathrm{~mm}$, whereas the ground length is $10.30 \mathrm{~mm}$. Moreover, the patch length, patch width, and ground width are 8,8 , and $19.02 \mathrm{~mm}$ respectively. As a result, the minimum reflection is $-27.6 \mathrm{~dB}$ and the bandwidth is $4.1025 \mathrm{GHz}$. After adding a rectangular slot, the minimum reflection reaches $-40.7 \mathrm{~dB}$ and the bandwidth is increased to $4.9577 \mathrm{GHz}$ if the patch length and width are empirically increased to $20 \mathrm{~mm}$. The best length and width of the slot are 2 and $10 \mathrm{~mm}$ respectively. Figures 23 and 24 show the design and results of the ground-front rectangular antenna without and with slot respectively.

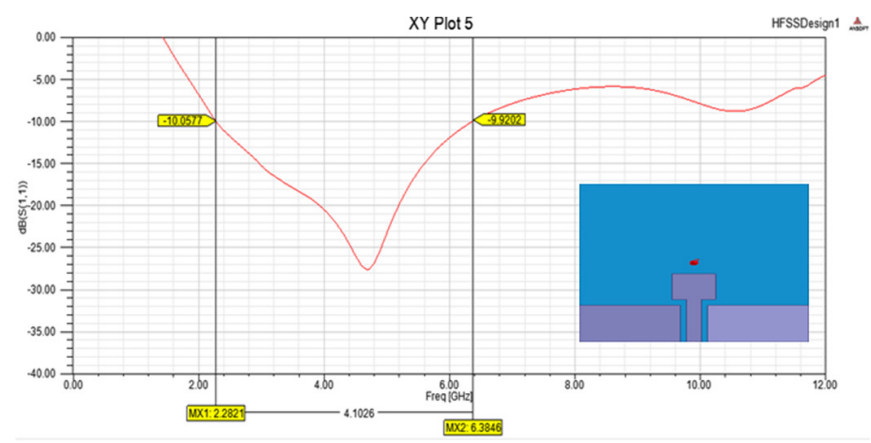

Fig. 23. Ground-front rectangular patch without slot. Design and results.

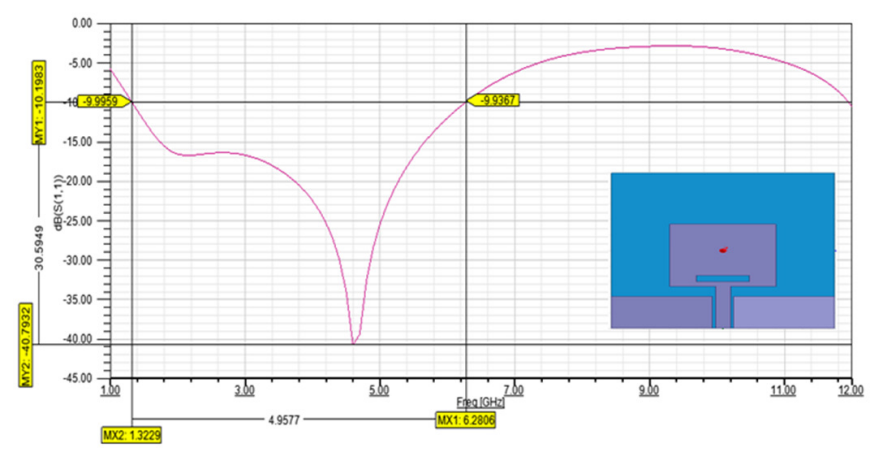

Fig. 24. Ground-front rectangular patch with slot. Design and results.

Tables I and II summarize the entire ground-back results while Tables III and IV summarize the entire ground-front results, for the different patch shapes without and with slot respectively.
TABLE I. GROUND-BACK RESULTS WITHOUT SLOT

\begin{tabular}{|c|c|c|c|c|}
\hline $\begin{array}{c}\text { Patch } \\
\text { shape }\end{array}$ & $\begin{array}{c}\boldsymbol{f}_{\boldsymbol{L}} \\
(\mathbf{G H z})\end{array}$ & $\begin{array}{c}\boldsymbol{f}_{\boldsymbol{H}} \\
(\mathbf{G H z})\end{array}$ & $\begin{array}{c}\text { Frequency } \\
\text { bandwidth } \\
(\mathbf{G H z})\end{array}$ & $\begin{array}{c}\text { Minimum } \\
\text { reflection coefficient } \\
(\mathbf{d B})\end{array}$ \\
\hline Triangular & 9.8728 & 10.5994 & 0.7266 & -16 \\
\hline Diamond & 1.4391 & 4.8431 & 3.404 & -13 \\
\hline Circular & 1.3107 & 8.5825 & 7.2718 & -18 \\
\hline Elliptical & 6.6880 & 9.6378 & 2.9498 & -16 \\
\hline Hexagonal & 7.0385 & $>12$ & $>4.9615$ & -14 \\
\hline Rectangular & 4.7137 & 9.555 & 4.8413 & -16 \\
\hline
\end{tabular}

TABLE II. GROUND-BACK RESULTS WITH SLOT

\begin{tabular}{|c|c|c|c|c|}
\hline $\begin{array}{c}\text { Patch } \\
\text { shape }\end{array}$ & $\begin{array}{c}\boldsymbol{f}_{\boldsymbol{L}} \\
(\mathbf{G H z})\end{array}$ & $\begin{array}{c}\boldsymbol{f}_{\boldsymbol{H}} \\
(\mathbf{G H z})\end{array}$ & $\begin{array}{c}\text { Frequency } \\
\text { bandwidth } \\
(\mathbf{G H z})\end{array}$ & $\begin{array}{c}\text { Minimum } \\
\text { reflection coefficient } \\
(\mathbf{d B})\end{array}$ \\
\hline Triangular & 6.7817 & 7.4187 & 0.637 & -36 \\
\hline Diamond & 1.9777 & 6.9354 & 4.9577 & -16.69 \\
\hline Circular & 1.5022 & $>12$ & $>10.4978$ & -25.108 \\
\hline Elliptical & 7.3144 & 9.7465 & 2.4321 & -20.1 \\
\hline Hexagonal & 1.8174 & 7.7773 & 5.9599 & -31.82 \\
\hline Rectangular & 4.7728 & 9.3909 & 4.6181 & -19.26 \\
\hline
\end{tabular}

TABLE III. GROUND-FRONT RESULTS WITHOUT SLOT

\begin{tabular}{|c|c|c|c|c|}
\hline $\begin{array}{c}\text { Patch } \\
\text { shape }\end{array}$ & $\begin{array}{c}\boldsymbol{f}_{\boldsymbol{L}} \\
(\mathbf{G H z})\end{array}$ & $\begin{array}{c}\boldsymbol{f}_{\boldsymbol{H}} \\
(\mathbf{G H z})\end{array}$ & $\begin{array}{c}\text { Frequency } \\
\text { bandwidth } \\
(\mathbf{G H z})\end{array}$ & $\begin{array}{c}\text { Minimum } \\
\text { reflection coefficient } \\
(\mathbf{d B})\end{array}$ \\
\hline Triangular & 1.3974 & 2.2821 & 0.8847 & -26 \\
\hline Diamond & 1.5769 & 3.8718 & 2.2949 & -16 \\
\hline Circular & 1.5759 & 11.9765 & 10.4006 & -37.8 \\
\hline Elliptical & 1.5171 & 5.5716 & 4.0545 & -28.3 \\
\hline Hexagonal & 1.4872 & 8.1154 & 6.6282 & -48 \\
\hline Rectangular & 2.2821 & 6.3846 & 4.1025 & -27.6 \\
\hline
\end{tabular}

TABLE IV. GROUND-FRONT RESULTS WITH SLOT

\begin{tabular}{|c|c|c|c|c|}
\hline $\begin{array}{c}\text { Patch } \\
\text { shape }\end{array}$ & $\begin{array}{c}\boldsymbol{f}_{\boldsymbol{L}} \\
(\mathbf{G H z})\end{array}$ & $\begin{array}{c}\boldsymbol{f}_{\boldsymbol{H}} \\
(\mathbf{G H z})\end{array}$ & $\begin{array}{c}\text { Frequency } \\
\text { bandwidth } \\
(\mathbf{G H z})\end{array}$ & $\begin{array}{c}\text { Minimum } \\
\text { reflection coefficient } \\
(\mathbf{d B})\end{array}$ \\
\hline Triangular & 1.3229 & 2.5657 & 1.2428 & -45.46 \\
\hline Diamond & 1.7971 & 4.7931 & 2.996 & -22 \\
\hline Circular & 1.4909 & 3.9295 & 2.4386 & -43.53 \\
\hline Elliptical & 1.6523 & 5.0415 & 3.3892 & -26.33 \\
\hline Hexagonal & 1.3280 & 8.0308 & 6.7028 & -63.82 \\
\hline Rectangular & 1.3229 & 6.2806 & 4.9577 & -40.79 \\
\hline
\end{tabular}

\section{CONCLUSIONS}

This paper presented ways to improve the resonance characteristics of a microstrip patch antenna in the SHF band. The study involved the addition of a slot into different patch shapes as well as moving the ground plane to the front side of the antenna. The HFSS software was used, and the results showed that the slot insertion and the use of front ground decreased the minimum power reflection significantly in most of the considered cases. That occurred due to the enhancement of electromagnetic fringing. As a result, the best reflection was achieved by the ground-front slotted hexagonal antenna since the minimum reflection coefficient reached $-63.82 \mathrm{~dB}$ whereas it was $-48 \mathrm{~dB}$ without a slot. Other good results were obtained by the ground-front slotted triangular, circular and rectangular antennas where the minimum reflection reached -45.46 , -43.53 , and $-40.79 \mathrm{~dB}$ respectively. In addition, the insertion of 
a slot resulted in improving the antenna bandwidth in most cases, including the ground-front triangular, ground-back diamond, ground-front diamond, ground-back circular, groundback hexagonal, ground-front hexagonal, and ground-front rectangular antennas. In conclusion, all the slotted designs presented in the paper are highly recommended for fabrication.

\section{ACKNOWLEDGMENT}

The authors are thankful to Ahmed Al-Rogi, Abdullah AlOtaibi, Khaled Al-Zhrani, and Abdulelah Al-Sulami for their assistance during the course of this work.

\section{REFERENCES}

[1] V. P. Patil, "Enhancement of Bandwidth of Rectangular Patch Antenna Using Two Square Slots Techniques," International Journal of Engineering Sciences \& Emerging Technologies, vol. 3, no. 2, pp. 1-12, 2012.

[2] L. Agarwal, S. Gandhi, S. Malik, S. Vijay, and T. S. Chauhan, "Design and analysis of rectangular patch with square slots," International Journal of Scientific Research and Management Studies, vol. 3, no. 1, pp. 15-20, 2016.

[3] S. Nelaturi and N. V. S. N. Sarma, "Compact Wideband Microstrip Patch Antenna based on High Impedance Surface," Engineering, Technology \& Applied Science Research, vol. 8, no. 4, pp. 3149-3152, Aug. 2018, https://doi.org/10.48084/etasr.1971.

[4] S. R. Emadian and J. Ahmadi-Shokouh, "Very Small Dual BandNotched Rectangular Slot Antenna With Enhanced Impedance Bandwidth," IEEE Transactions on Antennas and Propagation, vol. 63, no. 10, pp. 4529-4534, Oct. 2015, https://doi.org/10.1109/TAP.2015. 2456905.

[5] M. U. Khan, M. S. Sharawi, and R. Mittra, "Microstrip patch antenna miniaturisation techniques: a review," IET Microwaves, Antennas \& Propagation, vol. 9, no. 9, pp. 913-922, 2015, https://doi.org/10.1049/ iet-map.2014.0602.

[6] A. Chaudhary, D. C. Dhukaiya, "Analysis and bandwidth enhancement by cutting pi and rectangular slot in rectangular mictrostrip antenna for broadband applications", International Journal of Enhanced Research in Science Technology \& Engineering, Vol. 3, No. 1, pp. 431-437, 2014

[7] J. Ghosh, S. Ghosal, D. Mitra, and and S. R. B. Chaudhuri, "Mutual Coupling Reduction Between Closely Placed Microstrip Patch Antenna Using Meander Line Resonator," Progress In Electromagnetics Research Letters, vol. 59, pp. 115-122, 2016, https://doi.org/ 10.2528/PIERL16012202.

[8] C. Shi, J. Cui, Z. Renli, and Y. Han, "Diamond-shaped metasurface lowprofile wideband antenna," The Journal of Engineering, vol. 2019, no. 20, pp. 6566-6567, Jul. 2019, https://doi.org/10.1049/joe.2019.0246.

[9] M. A. Yusuf, B. J. Kwaha, I. Umar, I. Maina, G. Mohammed, and A. Salihu, "Line Fed Triangular Microstrip Patch Antenna for Bluetooth Application at $2.45 \mathrm{GHz}, "$ Physics Memoir - Journal of Theoretical \& Applied Physics, vol. 1, no. 1, pp. 22-30, Mar. 2019.

[10] A. O. Fadamiro, J. D. Ntawangaheza, O. J. Famoriji, Z. Zhang, and F. Lin, "Design of a Multiband Hexagonal Patch Antenna for Wireless Communication Systems," IETE Journal of Research, pp. 1-8, Oct. 2019, https://doi.org/10.1080/03772063.2019.1664340.

[11] Y.-H. Lee, E.-H. Lim, F.-L. Bong, and B.-K. Chung, "Bowtie-Shaped Folded Patch Antenna With Split Ring Resonators for UHF RFID Tag Design," IEEE Transactions on Antennas and Propagation, vol. 67, no. 6 , pp. 4212-4217, Jun. 2019, https://doi.org/10.1109/TAP.2019. 2908268.

[12] R. B. J. Chandra, I. Khan, G. D. Devanagavi, K. R. Sudhindra, and T. Ali, "A circular patch antenna loaded with three complementary ring slots (Crs) for uwb applications," Journal of Advanced Research in Dynamical and Control Systems, vol. 11, no. 1 Special Issue, pp. 12141220, Jan. 2019.

[13] K. N. Lal and A. K. Singh, "Modified design of microstrip patch antenna for WiMAX communication system," in IEEE Students' Technology
Symposium, Kharagpur, India, Mar. 2014, pp. 386-389, https://doi.org/ 10.1109/TechSym.2014.6808081.

[14] S. Yan and Y. Zheng, "Low-profile Annular Patch Antenna for Pattern Diversity Applications," in Photonics Electromagnetics Research Symposium - Fall, Xiamen, China, Dec. 2019, pp. 222-228, https://doi.org/10.1109/PIERS-Fall48861.2019.9021428.

[15] R. K. Verma and D. K. Srivastava, "Bandwidth enhancement of a slot loaded T-shape patch antenna," Journal of Computational Electronics, vol. 18, no. 1, pp. 205-210, Mar. 2019, https://doi.org/10.1007/s10825018-1277-7.

[16] L. Liu, W. Cheung, and T. I. Yuk, "Bandwidth Improvements Using Ground Slots for Compact UWB Microstrip-fed Antennas," in 30th Progress In Electromagnetics Research Symposium, Suzhou, China, Sep. 2011, pp. 1420-1423.

[17] H. F. AbuTarboush, H. S. Al-Raweshidy, and R. Nilavalan, "Bandwidth enhancement for microstrip patch antenna using stacked patch and slot," in International Workshop on Antenna Technology, Santa Monica, CA, USA, Mar. 2009, pp. 1-4, https://doi.org/10.1109/IWAT.2009.4906874.

[18] S. Mahmoud, W. Swelam, and M. Hassan, "Parametric Study of Slotted Ground Microstrip Patch Antenna," Journal of Electronics and Communication Engineering, vol. 2, no. 1, pp. 1-8, Feb. 2016.

[19] A. A. Deshmukh, A. Mhatre, M. Shah, C. Kudoo, and S. Pawar, "Wideband Designs of Unequal Lengths Slot Cut Microstrip Antennas Backed by Slotted Ground Plane," in Optical and Wireless Technologies, Singapore, 2020, pp. 363-369, https://doi.org/10.1007/ 978-981-15-2926-9 40.

[20] T. M. Kumar, N. R. Jonathan, P. Peshwe, S. Doddipalli, and A. Kothari, "An Annular Ring Antenna with Slotted Ground Plane for Dual Band Wireless Applications," in Advances in Decision Sciences, Image Processing, Security and Computer Vision, S. C. Satapathy, K. S. Raju, K. Shyamala, D. R. Krishna, and M. N. Favorskaya, Eds. New York, NY, USA: Springer, 2020, pp. 307-313.

[21] J. Yuan and Y. Li, "A Compact Circularly Polarized Microstrip Ring Antenna Using a Slotted Ground for GNSS Applications," Progress In Electromagnetics Research Letters, vol. 88, pp. 29-36, 2020, https://doi.org/10.2528/PIERL19082707.

[22] K.-F. Tong, K.-M. Luk, K.-F. Lee, and R. Q. Lee, "A broad-band U-slot rectangular patch antenna on a microwave substrate," IEEE Transactions on Antennas and Propagation, vol. 48, no. 6, pp. 954-960, Jun. 2000, https://doi.org/10.1109/8.865229.

[23] R. Jothi Chitra and V. Nagarajan, "Double L-slot microstrip patch antenna array for WiMAX and WLAN applications," Computers \& Electrical Engineering, vol. 39, no. 3, pp. 1026-1041, Apr. 2013, https://doi.org/10.1016/j.compeleceng.2012.11.024.

[24] C. Rajagopal, S. B. Suseela, N. Noorullakhan, and R. Sankararajan, "Compact modified 'T' slot circular patch quad band antenna for MIMO applications," International Journal of Microwave and Wireless Technologies, vol. 9, no. 4, pp. 865-873, May 2017, https://doi.org/ 10.1017/S1759078716000696.

[25] M. Shaw, B. Deb, and N. Mandal, "Circular Microstrip Patch Antenna with U-slots for multi band application," in 2nd International Conference on Electronics, Materials Engineering Nano-Technology, Kolkata, India, May 2018, pp. 1-3, https://doi.org/10.1109/ IEMENTECH.2018.8465227.

[26] S. Shekhar Naik and G. Shet, "Design and Simulation of Conventional and U-Slot Circular Microstrip Patch Antenna with and Without Air Gap for LTE Application," in 2nd International Conference on Trends in Electronics and Informatics, Tirunelveli, India, May 2018, pp. 126-131, https://doi.org/10.1109/ICOEI.2018.8553685.

[27] M. I. Khattak, A. Sohail, U. Khan, Z. Barki, and and G. Witjaksono, "Elliptical Slot Circular Patch Antenna Array with Dual Band Behaviour for Future 5G Mobile Communication Networks," Progress In Electromagnetics Research C, vol. 89, pp. 133-147, 2019, https://doi.org/10.2528/PIERC18101401.

[28] M. M. Nahas and M. Nahas, "Bandwidth and Efficiency Enhancement of Rectangular Patch Antenna for SHF Applications," Engineering, Technology \& Applied Science Research, vol. 9, no. 6, pp. 4962-4967, Dec. 2019, https://doi.org/10.48084/etasr.3014. 
[29] O. W. Ata, M. Salamin, and K. Abusabha, "Double U-slot rectangular patch antenna for multiband applications," Computers \& Electrical Engineering, vol. 84, Jun. 2020, Art. no. 106608, https://doi.org/ 10.1016/j.compeleceng.2020.106608.

[30] M. El-Sayed, N. Gad, M. El-Aasser, and A. Yahia, "Slotted Rectangular Microstrip-Antenna Design for Radar and 5 G Applications," in International Conference on Innovative Trends in Communication and Computer Engineering, Aswan, Egypt, Feb. 2020, pp. 330-334, https://doi.org/10.1109/ITCE48509.2020.9047754.

[31] H. Srivastava, A. Singh, A. Rajeev, and U. Tiwari, "Bandwidth and Gain Enhancement of Rectangular Microstrip Patch Antenna (RMPA) Using Slotted Array Technique," Wireless Personal Communications, vol. 114, no. 1, pp. 699-709, Sep. 2020, https://doi.org/10.1007/s11277-02007388-x.

[32] A. Kumar, J. Kaur, and R. Singh, "Performance Analysis of Different Feeding Techniques," International Journal of Emerging Technology and Advanced Engineering, vol. 3, no. 3, pp. 884-890, 2013.

[33] A. Arora, A. Khemchandani, Y. Rawat, S. Singhai, and G. Chaitanya, "Comparative study of different Feeding Techniques for Rectangular Microstrip Patch Antenna," International Journal of Innovative research in electrical, electronics, instrumentation and control Engineering, vol. 3, no. 5, pp. 32-35, 2015.

[34] S. Jensen, Microstrip Patch Antenna. Arizona, USA: Northern Arizona University, 2010.

[35] P. Cao, Y. Huang, J. Zhang, and Y. Lu, "A comparison of planar monopole antennas for UWB applications," in Loughborough Antennas Propagation Conference, Loughborough, UK, Nov. 2011, pp. 1-4, https://doi.org/10.1109/LAPC.2011.6114099. 